\title{
Anaplastic Oligodendroglioma, Not Otherwise Specified
}

National Cancer Institute

\section{Source}

National Cancer Institute. Anaplastic Oligodendroglioma, Not Otherwise Specified. NCI

Thesaurus. Code C129322.

An anaplastic oligodendroglioma in which there is insufficient information on the IDH genes and $1 p / 19 q$ codeletion status. 